Mohammed A and Cashell KA. Structural fire design of SHS, RHS and CHS high strength steel columns. Accepted for publication in Advances in Structural Engineering, 2021.

\title{
Structural fire design of SHS, RHS and CHS high strength steel columns
}

\author{
Asif Mohammed ${ }^{\mathrm{a}}$ and Katherine A. Cashell ${ }^{\mathrm{a}}$ \\ ${ }^{a}$ Department of Civil and Environmental Engineering, Brunel University London, UK
}

\section{Abstract}

Despite substantial progress in recent years to improve the design guidance for high strength steel (HSS) structural elements, this has mainly been for ambient conditions with their fire response still in need of further research. Accordingly, this paper reports on an investigation into the structural performance of unprotected HSS hollow section columns in fire. Finite element models of columns made from square, circular and rectangular hollow sections are developed and are validated against test data at ambient and elevated temperature. The validated models are employed to perform parametric studies to assess the influence of a range of variables such as the grades of HSS, levels of temperature exposure and cross-sectional geometry. The structural fire design resistance method for a column given in the Eurocode is assessed based on the FE results. Consequently, new buckling curves are proposed, which provide a more accurate prediction of the real capacity and reliability analysis is also performed on the new proposed design formulations.

Keywords: High strength steel, Hollow sections, Finite element modelling, Columns, Fire, Design

\section{Introduction}

In recent years, there have been significant improvements to available design guidance for HSS structures, as well as a greater emphasis given to the sustainability of a structure. These have developed from a series of research programmes including collaborative European projects [1-2], analysis of beams and columns [3-5], and also studies into various loading scenarios [6-7]. As a consequence, there is generally wider product availability and the use of high strength steel (HSS) in structural applications in growing. HSS offers environmental advantages compared with normal strength carbon steel due to the lower material requirements, which allows the use of slender members and more flexible design. HSS offers outstanding strength to weight ratio, which permits longer span members and lighter structural components, in comparison to conventional carbon steel. Despite the increase in demand for HSS in the construction industry, one of the main inhibitors to more widespread use is the shortage of reliable design information and codes, which allow structural engineers to harness the material's benefits fully. 
Mohammed A and Cashell KA. Structural fire design of SHS, RHS and CHS high strength steel columns. Accepted for publication in Advances in Structural Engineering, 2021.

HSS is defined as structural steel with a nominal yield strength between 460 and $700 \mathrm{~N} / \mathrm{mm}^{2}$ [89]. Eurocode 3 Part 1-12 [9] presents codified design rules for HSS, however, the code is devised based on the rules in EN 1993-1-1 [8] for normal strength carbon steels and uses many of the same design criteria, including for cross-sectional and member level design of structural elements. It is noteworthy that a key challenge in the design of HSS structural elements is the possibility of stability challenges when compressive stresses are introduced [3]. The Young's modulus of HSS is similar to that of normal strength carbon steel, but HSS has a higher yield strength, which leads to stability and serviceability concerns. In particular, during extreme loading conditions such as an earthquake or a fire, structures may be expected to undergo substantial inelastic deformations and, in this scenario, the resistance of HSS structures is essential to assess.

In fire conditions, it is vital for structural elements to maintain their function for prescribed periods of time, to allow for evacuation and rescue, etc. [10]. To date, there is a substantial amount of data in the literature on the behaviour of normal strength steel elements under fire conditions [e.g. 1115]. The outcomes of these studies have underpinned the development of structural fire design given in Eurocode 3 Part 1-2 [16]. In order to devise similar guidance for HSS structural elements, further research is essential to assess the applicability of existing design methods for normal strength steel members to ensure that designs are safe, reliable, and economical. Due to the high expenditure required for physical testing, especially at elevated temperature, there have only been limited studies into the flexural buckling behaviour of HSS columns under fire conditions [e.g. $17-18]$.

In this context, this paper makes a contribution to the state of the art on the behaviour of hollow section columns made from HSS in fire by examining the applicability of existing design guidance based on a large set of structural performance data generated through finite element analysis. The advantages of circular (CHS), square (SHS) and rectangular (RHS) hollow sections are well known, including their superior torsional resistance relative to open sections, their suitability for concrete infill, the pleasing aesthetic and their high levels of structural efficiency in compression. To investigate their behaviour in more detail, finite elements (FE) models are developed and described herein. The models are validated against available test data taken from the literature. Subsequently, parametric studies are performed to generate further structural performance data, and detailed comparisons are made between the FE-generated buckling resistances and the design values determined using the existing Eurocode 3 Part 1-2 [16] design code. Finally, the suitability of the current and proposed buckling curves is confirmed through a reliability analysis. 
Mohammed A and Cashell KA. Structural fire design of SHS, RHS and CHS high strength steel columns. Accepted for publication in Advances in Structural Engineering, 2021.

\section{Review of high strength steel (HSS) structures}

\subsection{Production methods and strengthening mechanisms}

There are a variety of ways of manufacturing HSS sections, including different heat treatments and rolling procedures. Structural steel is typically denoted by an S at the beginning of the name (e.g. S460N, etc.), followed by the yield strength in $\mathrm{N} / \mathrm{mm}^{2}$ and finally the method of manufacturing, where $\mathrm{N}, \mathrm{Q}, \mathrm{M}$ and $\mathrm{C}$ refer to materials that are normalised $(\mathrm{N})$, quench and tempered (Q), thermo-mechanically rolled or thermal-mechanical controlled processed (M) or cold-formed (C), respectively. In addition, there are different compositions of HSS which are employed to achieve the desired properties, including various alloying elements (e.g. magnesium, carbon, molybdenum, vanadium, niobium, etc.). The key point is that in order to increase the strength of the steel, it is necessary to reduce the movement of dislocations within the material microstructure. These dislocations can be reduced by the presence of alloying elements.

\subsection{Material properties}

The overall shape of the stress-strain response of HSS at ambient temperature is characterised by the initial Young's modulus $(E)$, nominal yield strength $\left(f_{y}\right)$, maximum strength $\left(f_{u}\right)$ and the corresponding maximum strain $\left(\varepsilon_{\mathrm{u}}\right)$. At elevated temperatures, the stress-strain response becomes increasingly nonlinear, with the stiffness and strength properties reducing. EN 1993 Part 1-2 [16] provides mechanical property retention factors which define how each of these terms varies with temperature. However, specific retention values for HSS are not included, and the designer must currently employ the values of normal strength steel. Figure 1 presents the retention factors for the effective yield strength at elevated temperature (i.e. $\mathrm{k}_{\mathrm{y}, \theta}=\mathrm{f}_{\mathrm{y}, \theta} / \mathrm{f}_{\mathrm{y}}$ ) based on the strength value corresponding to the $2 \%$ total strain $\left(f_{\mathrm{y}, \theta}\right)$ normalised by corresponding room temperature value $\left(\mathrm{f}_{\mathrm{y}}\right)$. The figure includes both the design guide values as well as some test data for S690QL and S700MC, reported elsewhere [19], based on isothermal material testing.

In terms of the material model, the Eurocode approach employs a 4 stage process to represent the stress-strain response at elevated temperatures $(\theta)$. The first phase is defined by the Young's modulus $\left(E_{\theta}\right)$ which applies until the proportional limit at $\theta\left(f_{p}, \theta\right)$ has been reached, the second phase employs an elliptical curve up to the nominal yield strength set at temperature $\left(f_{y, \theta}\right)$ which is reached at a strain of $\varepsilon_{\mathrm{y}, \theta}$ ( $2 \%$ total strain). The third phase involves a strength plateau between $\varepsilon_{\mathrm{y}, \theta}$ and a strain of $15 \%$ (specified as $\varepsilon_{\mathrm{t}, \theta}$ ) and finally, the stress declines to 0 at an ultimate strain $\left(\varepsilon_{\mathrm{u}, \theta}\right)$ value of $20 \%$. This procedure has been shown to sometimes overestimate the stress at certain levels of elevated temperature for some grades of HSS [5]. One shortcoming of this method is that the stress-strain response for some high strength steels can be overestimated in the region 
Mohammed A and Cashell KA. Structural fire design of SHS, RHS and CHS high strength steel columns. Accepted for publication in Advances in Structural Engineering, 2021.

between the proportional limit $\left(f_{p, \theta}\right)$ and yield point $\left(f_{y, \theta}\right)$, which may result in an overestimation of the buckling capacity of an HSS element in a fire scenario.

At elevated temperature, some researchers choose to employ the modified Ramberg-Osgood [5, 20] material model to represent the steel material response, which is an extension of the initial form [21] revised by Hill [22] for isothermal conditions. The advantages of this approach, compared with the Eurocode method, has been demonstrated $[13,23]$. In this material model, up to the $0.2 \%$ proof strength $\left(f_{0.2}\right)$, Equation 1 is used to determine the stress-strain response while at higher stresses beyond $0.2 \%$ proof strength $\left(f_{0.2}\right)$, Equation 2 is employed:

$$
\begin{gathered}
\varepsilon=\left(\frac{\sigma}{\mathrm{E}}\right)+0.002\left(\frac{\sigma}{\mathrm{f}_{0.2}}\right)^{\mathrm{n}} \text { for } \sigma \leq \mathrm{f}_{0.2} \\
\varepsilon=\left(\frac{\sigma-\mathrm{f}_{0.2 \mathrm{p}}}{\mathrm{E}_{0.2}}\right)+\left(\varepsilon_{1.0}-\varepsilon_{0.2}-\frac{\mathrm{f}_{1.0}-\mathrm{f}_{0.2}}{\mathrm{E}_{0.2}}\right) \times\left(\frac{\sigma-\mathrm{f}_{0.2}}{\mathrm{f}_{1.0}-\mathrm{f}_{0.2}}\right)^{\mathrm{m}}+\varepsilon_{0.2} \text { for } \sigma>\mathrm{f}_{0.2}
\end{gathered}
$$

In these expressions, $\sigma$ and $\varepsilon$ are the engineering stress and strain, respectively, $\mathrm{f}_{1.0}$ is the stress at $1 \%$ total strain, $\mathrm{E}_{0.2}$ is the tangent modulus at $\mathrm{f}_{0.2}, \varepsilon_{0.2}$ and $\varepsilon_{1.0}$ are the total strains at $\mathrm{f}_{0.2}$ and $\mathrm{f}_{1.0}$, respectively, $\varepsilon_{\mathrm{u}}$ is the strain at $\mathrm{f}_{\mathrm{u}}$ and $\mathrm{n}$ and $\mathrm{m}$ are the Ramberg-Osgood model parameters. Retention factors for each parameter in Equations 1 and 2 have been developed for both S690QL and S700MC HSS [19], and these are adopted together with Equations 1 and 2 for elevated temperature applications in the current paper.

\subsection{Element testing}

A number of researchers have examined the local and flexural buckling behaviour of HSS elements made using hollow sections [e.g. 24-27]. Ma et al. [24] focussed on cold-formed CHS stub-columns whilst Wang et al. [25] examined the cross-sectional response of hot-rolled SHS and RHS sections. Wang and Gardner [26] presented the results from a series of tests on SHS columns under pure axial compression, and Pournara et al. [27] performed tests on CHS columns and beam-columns. However, it is noteworthy that all for the test data available in the literature is on the ambient response of HSS members, with no test data available on HSS hollow section columns under fire conditions.

\section{Finite element modelling}

\subsection{General}

In this section, the details of a three-dimensional finite element (FE) model are described. The model is developed in order to gain a greater insight into the behaviour of hollow section columns made from HSS, in fire conditions. It is developed using the commercial software ABAQUS [28] 
Mohammed A and Cashell KA. Structural fire design of SHS, RHS and CHS high strength steel columns. Accepted for publication in Advances in Structural Engineering, 2021.

and is capable of capturing the structural behaviour of HSS hollow sections at elevated temperature. The analysis is based on the available test data in the literature, to enable validation of the numerical approach. Thereafter, the FE model is employed to assess the influence of the most salient properties on the ultimate performance. Three different types of cross-sections are considered in this study, namely square (SHS), rectangular (RHS), and circular (CHS) hollow sections, respectively.

The FE analysis is conducted using the Abaqus/Standard analysis procedure and comprises two stages which are performed in sequential order. Firstly, an elastic buckling analysis is performed to determine the buckling mode shape using the *BUCKLE step procedure. In the second phase, a nonlinear analysis step is performed using the modified *RIKS method in ABAQUS [28], including the initial geometric imperfections determined from the elastic buckling analysis, to determine the structural response under load. Both the material and geometric nonlinearities are accounted for in the analysis. At elevated temperature $(\theta)$, the columns are modelled under isothermal elevated temperature conditions. This is achieved following the same procedure as ambient temperature; however, the stress-strain data corresponding to a given temperature $\theta$ is employed to the FE model.

\subsection{Summary of tests from the literature}

Due to the absence of HSS hollow sections tests under fire conditions in the literature, the FE models are validated using the results from the ambient temperature tests on HSS columns reported by Wang and Gardner [26] and Pournara et al. [27] and the data from the elevated temperature tests on columns made from normal strength steel reported by Pauli et al. [13, 29]. All of these tests were performed under isothermal temperature conditions. Between all of these test series, the critical behavioural and structural response aspects relevant to HSS columns at elevated temperature are examined and validated.

The tests performed and reported by Wang and Gardner [26] included a series of columns made from hot-finished S460 and S690 square hollow sections (SHS). The columns were pinned at both ends and allowed in-plane rotation at one axis only. The columns were loaded under displacement control at a rate of $\mathrm{L}_{\mathrm{cr}} / 2000$ per minute, where $\mathrm{L}_{\mathrm{cr}}$ is the effective buckling length of the specimens. Thirty columns were tested in total, all of which are examined in the current study for validation of the numerical approach. A summary of the key details is presented in Table 1; this includes the measured heights (h), widths (b) and thicknesses ( $t$ ) of the sections, the inner radius of the corner region of the cross-sections $\left(\mathrm{r}_{\mathrm{i}}\right)$, the global geometric imperfection amplitude $\left(\omega_{0}\right)$ and the failure load measured during the test $\left(\mathrm{N}_{\mathrm{u}, \text { test }}\right)$. 
Mohammed A and Cashell KA. Structural fire design of SHS, RHS and CHS high strength steel columns. Accepted for publication in Advances in Structural Engineering, 2021.

On the other hand, Pournara et al. [27] performed four tests on S590 CHS columns at ambient temperature under pure compression, as part of a more extensive test programme which also considered beam-columns. The key details are presented in Table 2, including the nominal section diameter $\left(\mathrm{D}_{\text {nom }}\right)$ and the inner diameter $\left(\mathrm{D}_{\text {inner }}\right)$. These columns were loaded in displacement control at a constant rate of $1.7 \mathrm{~mm} / \mathrm{min}$.

Pauli et al. $[13,29]$ performed elevated temperature tests on SHS and RHS columns made from S355 carbon steel under isothermal conditions, as part of an extensive test programme. The test series comprised short and long columns, each of which was first heated to a target temperature $\theta$ of 400,550 or $700{ }^{\circ} \mathrm{C}$. Then, once thermal equilibrium had been established at the desired temperature of the columns, a mechanical load was applied at a strain rate of $0.1 \% / \mathrm{min}$ until the horizontal displacement increased rapidly and the vertical load could no longer be sustained. The key details of these tests are reported in Table 3, including the load at failure, $\mathrm{N}_{\mathrm{u}, \text { test, } \theta}$.

\subsection{Development of the FE model}

The geometry of the HSS columns implemented in the FE model is based on the measured values given in the literature where possible; when this data is unavailable, the nominal dimensions are employed. The HSS members are modelled using shell elements known as S4R in the ABAQUS library [28]. The size of the shell elements is based on the results of a mesh sensitivity study and, accordingly, for the SHS and RHS, an element size equal to the cross-section thickness is assigned to the flat regions of the sections, whilst a finer mesh of four elements per cross-section thickness is employed in the corner regions; for the CHS the element size equal to the cross-section thickness is adopted. The boundary conditions are appropriately defined to simulate either fixed or pinned support conditions. For the fixed end boundary conditions, all translational degrees of freedom apart from axial displacement at the loaded end are restrained, and all rotational degrees of freedom at both ends are restrained. For pin-ended boundary conditions, all translational degrees of freedom, apart from axial displacement at the loaded end, are restrained, whereas the rotational degrees of freedom are also restrained at both ends, except those associated with the plane of buckling. Loading is applied through a reference point at the top of each column FE model in a concentric manner.

Due to the tests being performed under isothermal conditions, the elevated temperature material properties are applied uniformly through the thickness of the member. In each of the test programmes, a number of tensile tests were performed on the HSS to obtain the real material stress-strain response, and these are depicted in the model. For the SHS and RHS steel columns reported by Pauli et al. [13] at elevated temperature, the two-stage modified material model 
Ramberg-Osgood revised by Gardner and Nethercot [20] depicted in Equations 1 and 2 previously is employed to develop the full-range stress-strain response. The possible strength enhancement which may exist in the corner regions of the section are not included in the model as it was previously shown [25] that this has a negligible effect for these types of section and the overall performance. ABAQUS [28] requires the measured engineering stress-strain curve to be transformed into true stress $\left(\sigma_{\text {true }}\right)$ versus $\log$ plastic strain $\left(\varepsilon_{\ln }^{\mathrm{pl}}\right)$ response, as given in Equations 3 and 4 , respectively, where $\sigma_{\text {nom }}$ is the engineering stress, $\varepsilon_{\text {nom }}$ is the engineering strain and $E$ is Young's modulus.

\begin{tabular}{|c|c|}
\hline$\sigma_{\text {true }}=\sigma_{\text {nom }}\left(1+\varepsilon_{\text {nom }}\right)$ & (3) \\
\hline$\varepsilon_{\ln }^{\mathrm{pl}}=\ln \left(1+\varepsilon_{\text {nom }}\right)-\frac{\sigma_{\text {true }}}{\mathrm{E}}$ & (4) \\
\hline
\end{tabular}

The modelling approach accounts for initial global and local geometric imperfections. Similar to previous studies on HSS [26, 27], the geometric imperfections are incorporated in the numerical models in the form of the lowest elastic buckling mode shape, obtained from a linear buckling analysis and the amplitudes which were measured values during the test programmes. On the other hand, residual stresses are not included as their influence on the overall behaviour of hollow sections is minimal [26].

\subsection{Validation of FE model}

The FE models are validated against the test results reported in Tables 1 [26], 2 [27] and 3 [13, 29]. The results of the FE models and test results are assessed by comparing the load-deformation response, ultimate failure load and failure modes. Similar procedures are employed for both the ambient and elevated temperature validations by incorporating the material properties corresponding to the test temperature under consideration. Both Tables 1 and 2 also include the ratio of the FE ultimate load $\left(\mathrm{N}_{\mathrm{u}, \mathrm{FE}}\right)$ to the corresponding ultimate test load $\left(\mathrm{N}_{\mathrm{u}, \text { test }}\right)$. The mean value of the $\mathrm{N}_{\mathrm{u}, \mathrm{FE}} / \mathrm{N}_{\mathrm{u} \text {,est }}$ ratio for SHS and CHS columns is shown to be 1.01 and 0.92 , respectively, whilst the corresponding coefficients of variance (COV) values are of 0.06 and 0.02 .

Figure 2 presents the load versus lateral deflection responses from both the numerical model and the experiments for (a) SHS [26] and (b) CHS [27] columns. All of the tests listed in Tables 2 and 3 were modelled, and a selection of data are presented in the figures for illustrative purposes. The numerical model is observed to provide an accurate depiction of the load-deformation behaviour for the HSS columns both with a square and circular hollow cross-section. This is further evidenced by the $\mathrm{N}_{\mathrm{u}, \mathrm{FE}} / \mathrm{N}_{\mathrm{u}, \text { test }}$ ratios provided in Tables 1 and 2 . The FE model provides a mean 
Mohammed A and Cashell KA. Structural fire design of SHS, RHS and CHS high strength steel columns. Accepted for publication in Advances in Structural Engineering, 2021.

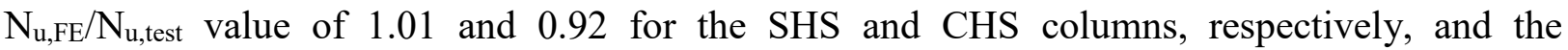
corresponding coefficient of variation (COV) values of 0.06 and 0.02 , respectively. The global buckling failure modes from the numerical studies are also in good agreement with those from experiments, as shown in Figure 3. From the results provided in Tables 1 and 2, it is concluded that the FE models are adequate of predicting the ultimate strength of HSS columns at room temperature.

For the elevated temperature response, Figure 4 presents the load versus axial displacement for two of the tested specimens including (a) a stub column and (b) a slender member, with the corresponding FE analysis. In addition, the ratio of the $\mathrm{FE}$ ultimate load $\left(\mathrm{N}_{\mathrm{u}, \mathrm{FE}, \theta}\right)$ to the ultimate test load $\left(\mathrm{N}_{\mathrm{u}, \text { test }, \theta}\right)$ is given in Table 3. For the stub columns, the numerical model provides a mean $\mathrm{N}_{\mathrm{u}, \mathrm{FE}, \theta} / \mathrm{N}_{\mathrm{u}, \text { test }, \theta}$ value of 1.00 and COV of 0.05 . On the other hand, for the slender columns, the numerical model provides a mean $\mathrm{N}_{\mathrm{u}, \mathrm{FE}, \theta} / \mathrm{N}_{\mathrm{u}, \text { test, }, \theta}$ value of 1.00 and a $\mathrm{COV}$ of 0.07 . In terms of the failure mode, Figure 5 presents the deformed shape from the test specimens L6 and L10 [29] after the fire test together with the corresponding numerical model simulation. The failure mode in the test was a combination of local and global buckling for L6 and global buckling for L10, and the model clearly well simulates this.

The load-axial displacement responses demonstrated in Figure $4 \mathrm{a}$ and $4 \mathrm{~b}$ show that the FE model traces the behaviour of the columns reasonably well. The comparison presented in Table 3 demonstrate underestimation of the ultimate load of the HSS hollow section and hence provide a safe fire resistance prediction for the steel columns. There are some relatively small discrepancies between the experimental and numerical values as well as the overall behaviour and these are most likely due to differences in the geometric and imperfection values used in the model compared with the physical specimens, and also the use of idealised boundary conditions in the model. In addition, with fire testing, there are many factors and variables which can occur during the test and these are not easy to measure or simulate accurately. Nevertheless, the key conclusion is that the FE model can capture the overall behaviour and provide a realistic estimation of the ultimate strength of hollow section HSS columns under isothermal conditions.

\section{HSS columns at elevated temperature}

In this section, the validated FE model is employed to perform a thorough parametric study, in which the most influential parameters to the ultimate performance are examined. Following this, the predicted FE resistance values are examined to evaluate the suitability of existing structural fire design guidance provided in Eurocode 3 Part 1-2 [16] and to propose more appropriate criteria 
Mohammed A and Cashell KA. Structural fire design of SHS, RHS and CHS high strength steel columns. Accepted for publication in Advances in Structural Engineering, 2021.

where required. The parameters considered for this study are presented in Table 4 and include the material grade, cross-section geometry and member length. Two HSS grades are selected, namely S690QL and S700MC, three cross-sectional shapes (SHS, RHS and CHS) and a number of member lengths given a range of non-dimensional slenderness's $\left(\bar{\lambda}_{\theta}\right)$ between 0.1 and 2.2 . The cross-sections have all been classified as fully effective in accordance with Eurocode 3 Parts 1-1 [8] and 1-2 [16].

The HSS material properties at elevated temperature reported by Winful et al. [5] are used in this study, which are provided in Table 5 and 6 for S690QL and S700MC, respectively. The two-stage modified Ramberg-Osgood material model provided in Equations 1 and 2 is employed to idealise the full-range stress-strain response for HSS at elevated temperatures. The lowest local buckling mode shape is utilised to perturb the geometry of the stub columns, while both the first local and first global mode shapes are introduced as geometric imperfections in the flexural buckling models. The value of the global imperfection is taken as $\mathrm{L} / 1000$, where $\mathrm{L}$ is the column length, in accordance to EN 1993-1-2 [16]. The local imperfection amplitude $\left(\omega_{0}\right)$ is defined using the Dawson and Walker model for the SHS and RHS cross-sections, as has been used for similar studies [24-25, 30]. This is presented in Equation 5 in which $t$ is the cross-section thickness and $\mathrm{f}_{\mathrm{cr}}$ is the elastic critical buckling stress of the most slender constituent plate element in the section:

$$
\omega_{0}=0.028 \mathrm{t}\left(\mathrm{f}_{\mathrm{y}} / \mathrm{f}_{\mathrm{cr}}\right)^{0.5}
$$

For the CHS, the local imperfection amplitude value is taken as $0.008 \mathrm{D}$, where $\mathrm{D}$ is the outer diameter, in accordance with other researchers [31-32]. Due to the symmetry of the cross-section, length and boundary conditions of the columns, half of the cross-section and half of the member length, is simulated.

Figure 6 presents the buckling curves for all of the simulated SHS, RHS and CHS columns made from (a) S690QL and (b) S700MC HSS, respectively. These figures show the ultimate load at temperature predicted by the FE model $\left(\mathrm{N}_{\mathrm{u}, \mathrm{FE}, \theta}\right)$ normalised by the corresponding elevated temperature yield load of the cross-section (i.e. $\mathrm{Ak}_{2, \theta} \mathrm{f}_{\mathrm{y}}$, where $\mathrm{A}$ is the cross-sectional area) and plotted against the elevated temperature member slenderness $\left(\bar{\lambda}_{\theta}\right)$. The mean, minimum, maximum and coefficient of variation (COV) values for the ratios of the ultimate loads obtained from the numerical parametric models $\left(\mathrm{N}_{\mathrm{u}, \mathrm{FE}, \theta}\right)$ and the predicted capacities $\left(\mathrm{N}_{\mathrm{u}, \mathrm{EC}, \theta}\right)$ obtained from EN 1993-1-2 [16] are presented in Table 7. The observed failure models are dependent on the slenderness $\left(\bar{\lambda}_{\theta}\right)$ of the specimen. When $\bar{\lambda}_{\theta}$ is less than 0.3 , local buckling dominates whereas 
Mohammed A and Cashell KA. Structural fire design of SHS, RHS and CHS high strength steel columns. Accepted for publication in Advances in Structural Engineering, 2021.

global buckling failure occurs at greater values of $\bar{\lambda}_{\theta}$. It is clear that the Eurocode generally underpredicts the buckling resistance for hollow-section columns made from S700MC HSS for all modelled temperatures and all cross-sectional shapes. This is because the stiffness and strength properties of S700MC at elevated temperature are better than those given in the code. As shown in Figure 6b, for these columns, the buckling resistance is over-predicted for members that reach temperatures greater than $800^{\circ} \mathrm{C}$.

Overall, the Eurocode generally provides a conservative depiction of the buckling capacity for all examined columns below $800^{\circ} \mathrm{C}$. It is noteworthy that in general there is less scatter for the columns made from S700MC compared with those made from S690QL. This is owing to the nonlinearity of the material constitutive behaviour, which can influence the stability of the column. The mechanical properties of S700MC (refer to Table 6) demonstrate that the material response is quite nonlinear, with a relatively low strain hardening exponent (n), and remains almost constant at all temperatures, in comparison to S690QL (Table 5). For hollow section columns with a non-dimensional slenderness value greater than unity, those made from S690QL and S700MC are shown to buckle in the elastic region, where the average stiffness falls in the elastic part of the stress-strain curve and, as expected, there is little difference between the elevated temperature buckling strengths for each HSS grade examined. It is clear that, in general, the Eurocode depicts the behaviour and design reasonably well, although there is scope for improvement, which would result in excellent material efficiency.

In this context, and based on the data presented in this paper, two new buckling curves are proposed for the elevated temperature buckling behaviour of columns made from S690QL and S700MC HSS, with SHS, RHS and CHS cross-sections. The proposed flexural buckling resistance $\left(\mathrm{N}_{\mathrm{u}, \text { prop }, \theta}\right)$ is determined using a similar procedure as given in Eurocode 3 Part 1-2 [16], but changing the imperfection factors $(\alpha)$ from the current value of 0.65 [16] to 0.6 for S690QL and 0.45 for S700MC, respectively. The new buckling curves are depicted in Figure 6 presented as a red dashed line. Using this curve rather than the current Eurocode guidance leads to a reduction in scatter and a more accurate assessment of the overall buckling resistance. Further results are presented in Table 7, including the mean, minimum, maximum and COV values of the $\mathrm{N}_{\mathrm{u}, \mathrm{FE}, \theta} / \mathrm{N}_{\mathrm{u}, \text { prop, },}$ ratio which shows a closer representation of the real buckling resistance for the specimens examined. 
Mohammed A and Cashell KA. Structural fire design of SHS, RHS and CHS high strength steel columns. Accepted for publication in Advances in Structural Engineering, 2021.

\section{Reliability Analysis}

In order to propose the buckling curves described in the previous section for design purposes, it is essential to conduct a reliability analysis to provide designers with confidence in their accuracy. As such, a statistical analysis is conducted to assess the reliability level of the existing and proposed structural fire design methods for hollow section columns made from S690QL and S700MC HSS, in accordance with the reliability criteria set out by Kruppa [33]. A schematic representation of the reliability criteria set out by Kruppa [33] is presented in Figure 7. This method employs three separate criteria to evaluate the reliability of the theoretical resistance values $\mathrm{r}_{\mathrm{ti}}$ for the considered design method relative to the comparable experimental (or numerical) values $r_{e i}$, and there are given as:

- Criterion 1: The percentage of the theoretical resistance values $r_{\mathrm{ti}}$ on the unsafe side by more than $15 \%$ of the experimental (or $\mathrm{FE}$ ) values $\mathrm{r}_{\mathrm{ei}}$ i.e. $\mathrm{r}_{\mathrm{ti}}>1.15 \mathrm{r}_{\mathrm{e} i}$, which should be zero.

- Criterion 2: The percentage of the theoretical resistance values $r_{t i}$ on the unsafe side i.e. $r_{t i}>$ $1.0 \mathrm{r}_{\mathrm{e}}$, which should be less than $20 \%$.

- Criterion 3: The mean value of all percentage difference between the theoretical resistance values $r_{t i}$ and the experimental (or numerical) values $r_{e i}$ which should be on the safe side and less than zero.

Table 8 presents the reliability assessment for the existing Eurocode 3 Part 1-2 [16] design procedures, as well as the newly proposed methods. It is shown from the data presented that the current Eurocode design guidance and the proposed buckling curves pass all of the criteria set out by Kruppa [33]. However, the proposed design expressions result in more accurate flexural buckling resistance predictions, indicating that the proposed methods provide reliable and more precise resistance predictions for SHS, RHS and CHS under compression at elevated temperatures with a value of $\gamma_{\mathrm{M}, \mathrm{fi}}$ equal to unity. At the present time, when the importance of sustainability is ever-growing, providing efficient design methods and procedures which allow for less material usage, is essential.

\section{Conclusions}

This paper provides a thorough analysis of the elevated temperature behaviour of columns with different hollow cross-sectional shapes, made from HSS. An FE model is developed and validated based on existing test data and then employed to assess the key behavioural aspects. It is shown that current Eurocode design methods generally provide conservative and reliable results, apart from for members made from S690QL at high temperatures. However, there is also a high degree 
Mohammed A and Cashell KA. Structural fire design of SHS, RHS and CHS high strength steel columns. Accepted for publication in Advances in Structural Engineering, 2021.

of scatter in the results, and therefore a new set of buckling curves is proposed. The proposed buckling curves provide a more accurate and reliable prediction of the flexural buckling resistance with a lower degree of scatter, in comparison with the existing Eurocode 3 design guidance. Also, the accuracy of the current and proposed design methods is assessed based on the three reliability criteria set out by Kruppa [33] and both satisfy the specified safety levels. However, the newly proposed method provides a more sustainable solution as is less conservative and results in a more efficient use of materials.

\section{References}

[1] European Commission, Rules on High Strength Steel (RUOSTE) Final Report, Brussels, Belgium, 2016.

[2] European Commission, High Strength Long Span Structures (HILONG) Final Report, Brussels, Belgium, 2017.

[3] H. Varol, K.A. Cashell, Numerical modelling of high strength steel beam at elevated temperature. Fire Safety Journal. 89 (2017) 41-50

[4] J. Wang, S. Afshan, M. Gkantou, M. Theofanous, C. Baniotopoulos, L. Gardner, Flexural behaviour of hot-finished high strength steel square and rectangular hollow sections. Journal of Construction Steel Research. 121 (2016) 97-109

[5] D. Winful, K. Cashell, S. Afshan, A. Barnes, R. Pargeter, Behaviour of high strength steel columns under fire conditions. Journal of Construction Steel Research. 150 (2018) 392-404.

[6] F. Javidan, A. Heidarpour, X. Zhao, H. Fallahi, Fundamental behaviour of high strength and ultra-high strength steel subjected to low cycle structural damage. Engineering Structures. 143 (2017) 427-440

[7] F. Hu, G. Shi, Y. Shi, Experimental study on seismic behavior of high strength steel frames: global response. Engineering Structures. 131 (2017) 163-179

[8] European Committee for Standardisation, EN 1993-1-1:2018 Eurocode 3 - Design of Steel Structures-Part 1-1: General Rules and Rules for Buildings, (2018).

[9] European Committee for Standardisation, EN 1993-1-12:2007 Eurocode 3 - Design of Steel Structures-Part 1-12: Additional Rules for the Extension of EN 1993 up to Steel Grades S 700, (2007). 
Mohammed A and Cashell KA. Structural fire design of SHS, RHS and CHS high strength steel columns. Accepted for publication in Advances in Structural Engineering, 2021.

[10] BS 9999, Fire Safety in the Design, Management and Use of Buildings - Code of Practice, BSI, 2017.

[11] D. Talamona, J.M. Franssen, J.B. Schleich. J. Kruppa, Stability of steel columns in case of fire: numerical modelling. Journal of Structural Engineering. 123 (1997) 713-720.

[12] J.-M. Franssen, D. Talamona, J. Kruppa, L.G. Cajot, Stability of steel columns in case of fire: experimental evaluation. Journal of Structural Engineering. 124 (1998) 158-163

[13] J. Pauli, D. Somaini, M. Knobloch, M. Fontana, Experiments on steel columns under fire conditions. Swiss Federal Institute of Technology Zurich, Institute of Structural Engineering, 2012.

[14] I.W. Burgess, A.O. Olawale, R.J. Plank, Failure of steel columns in fire. Fire Safety Journal. 18 (1992) 183-201

[15] K.C. Yang, R. Hsu, Structural behavior of centrally loaded steel columns at elevated temperature, Journal of Construction Steel Research. 65 (2009) 2062-2068

[16] EN 1993-1-2, Eurocode 3, Design of Steel Structures - Part 1-2: General Rules - Structural Fire Design, 2005.

[17] J. Chen, B. Young, Design of high strength steel columns at elevated temperatures, Journal of Construction Steel Research. 64 (2008) 689-703,

[18] W. Wang, Y. Ohmiya, G. Ma, Fire resistance study of axially loaded high strength steel columns, Procedia Engineering. 62 (2013) 690-701

[19] D.W. Winful, K.A. Cashell, S. Afshan, A.M. Barnes, R.J. Pargeter, Elevated temperature material behaviour of high-strength steel, Proceedings of the Institution of Civil Engineers Structures and Buildings (2017) 1-11.

[20] L. Gardner, D. Nethercot, Experiments on stainless steel hollow sections-part 1: material and cross-sectional behaviour, Journal of Constructional Steel Research. 60 (2004) 1291-1318

[21] W. Ramberg, W. R. Osgood, (1943). Description of stress-strain curves by three parameters. Technical Note No. 902, National Advisory Committee for Aeronautics. Washington, D.C.

[22] Hill, H. N. (1944). Determination of stress-strain relations from the offset yield strength values. Technical Note No. 927, National Advisory Committee for Aeronautics. Washington, D.C. 
Mohammed A and Cashell KA. Structural fire design of SHS, RHS and CHS high strength steel columns. Accepted for publication in Advances in Structural Engineering, 2021.

[23] M. Knobloch, J. Pauli, M. Fontana. Influence of the strain-rate on the mechanical properties of mild carbon steel at elevated temperatures. Material and Design. 49 (2013) 553-565.

[24] J.L. Ma, T.M. Chan, B. Young, Experimental investigation on stub-column behavior of coldformed high-strength steel tubular sections, J. Struct. Eng. 142 (5) (2016), 04015174. [16] J. Wang, S.

[25] J. Wang, S. Afshan, N. Schillo, M. Theofanous, M. Feldmann, L. Gardner, Material properties and compressive local buckling response of high strength steel square and rectangular hollow sections, Engineering Structures. 130 (2017) 297-315.

[26] J. Wang, L. Gardner, Flexural buckling of hot-finished high-strength steel SHS and RHS columns. Journal of Structural Engineering. ASCE 143 (2017) 1-12

[27] A.E. Pournara, S. A. Karamanos, E. Mecozzi, A. Lucci. Structural resistance of high-strength steel CHS members. Journal of Constructional Steel Research. 128 (2017) 152-165

[28] Dassault Systèmes, Abaqus Online Documentation, 2019.

[29] J. Pauli, D. Somaini, M. Knobloch, M. Fontana, Experiments on steel columns under fire conditions Appendices. Swiss Federal Institute of Technology Zurich, Institute of Structural Engineering, 2012.

[30] R.G. Dawson, A.C. Walker, Post-buckling of geometrically imperfect plates, Journal of Structural Division. 98 (1972) 75-94.

[31] A. Mohammed, S. Afshan, Numerical modelling and fire design of stainless steel hollow section columns. Thin-Walled Structures, 144 (2019) 106243

[32] EN 1993-1-5 Eurocode 3, Design of Steel Structures - Part 1-5: Plated Structural Elements, European Committee for Standardization, Brussels, 2006.

[33] J. Kruppa, Eurocodes-Fire parts. Proposal for a methodology to check the accuracy of assessment methods, CENTC250, Horizonal Group Fire, Document no: 99/130,1999. 
Table 1: Details of ambient tests on SHS columns made from S460 and S690 high strength steel [26]

\begin{tabular}{|c|c|c|c|c|c|c|c|c|c|c|}
\hline Specimens & Label & $\begin{array}{c}\mathrm{L}_{\mathrm{cr}} \\
(\mathrm{mm})\end{array}$ & $\begin{array}{c}\mathrm{h} \\
(\mathrm{mm})\end{array}$ & $\begin{array}{c}\mathrm{b} \\
(\mathrm{mm})\end{array}$ & $\begin{array}{c}\mathrm{t} \\
(\mathrm{mm}) \\
\end{array}$ & $\begin{array}{c}\mathrm{r}_{\mathrm{i}} \\
(\mathrm{mm})\end{array}$ & $\begin{array}{c}\omega_{0} \\
(\mathrm{~mm}) \\
\end{array}$ & $\begin{array}{c}\mathrm{N}_{\mathrm{u}, \text { test }} \\
(\mathrm{kN})\end{array}$ & $\begin{array}{l}\mathrm{N}_{\mathrm{u}, \mathrm{FE}} \\
(\mathrm{kN}) \\
\end{array}$ & $\mathrm{N}_{\mathrm{u}, \mathrm{FE}} / \mathrm{N}_{\mathrm{u}, \mathrm{test}}$ \\
\hline \multirow{8}{*}{$\begin{array}{l}\text { S460 SHS } \\
50 \times 50 \times 5\end{array}$} & C1L1 & 427.0 & 50.33 & 50.32 & 4.98 & 2.02 & 0.42 & 427.0 & 424 & 0.99 \\
\hline & C1L2 & 668.5 & 50.23 & 50.36 & 4.69 & 2.31 & 0.70 & 396.0 & 392 & 0.99 \\
\hline & C1L3 & 907.0 & 50.48 & 50.44 & 4.95 & 2.05 & 0.93 & 384.0 & 386 & 1.01 \\
\hline & C1L4 & 1220.0 & 50.26 & 50.36 & 4.63 & 2.37 & 1.16 & 282.0 & 298 & 1.06 \\
\hline & C1L5 & 1529.0 & 50.43 & 50.43 & 4.89 & 2.11 & 1.45 & 217.0 & 224 & 1.03 \\
\hline & C1L6 & 1700.0 & 50.37 & 50.52 & 5.01 & 2.00 & 1.75 & 182.0 & 186 & 1.02 \\
\hline & C1L7 & 1859.0 & 50.32 & 50.32 & 5.05 & 1.95 & 1.86 & 151.0 & 156 & 1.03 \\
\hline & C1L8 & 2150.0 & 50.37 & 50.39 & 4.92 & 2.08 & 2.21 & 126.0 & 120 & 0.95 \\
\hline \multirow{8}{*}{$\begin{array}{l}\text { S460 SHS } \\
70 \times 70 \times 6.3\end{array}$} & $\mathrm{C} 2 \mathrm{~L} 1$ & 649.5 & 70.00 & 69.96 & 6.22 & 3.78 & 0.64 & 792.0 & 782 & 0.99 \\
\hline & $\mathrm{C} 2 \mathrm{~L} 2$ & 939.0 & 69.90 & 69.95 & 6.29 & 3.72 & 0.94 & 762.0 & 767 & 1.01 \\
\hline & C2L3 & 1280.0 & 69.99 & 69.97 & 6.37 & 3.63 & 1.17 & 651.0 & 732 & 1.12 \\
\hline & C2L4 & 1710.0 & 69.83 & 69.91 & 6.32 & 3.68 & 1.8 & 531.0 & 569 & 1.07 \\
\hline & C2L5 & 2150.0 & 69.96 & 70.06 & 6.32 & 3.69 & 2.34 & 367.0 & 401 & 1.09 \\
\hline & C2L6 & 2400.0 & 69.95 & 70.02 & 6.21 & 3.79 & 2.53 & 309.0 & 328 & 1.06 \\
\hline & C2L 7 & 2600.0 & 69.95 & 70.07 & 6.17 & 4.34 & 2.67 & 264.0 & 281 & 1.06 \\
\hline & C2L8 & 3020.0 & 70.00 & 70.02 & 6.37 & 3.63 & 3.08 & 208.0 & 218 & 1.05 \\
\hline \multirow{3}{*}{$\begin{array}{l}\text { S460 SHS } \\
100 \times 100 \times 5\end{array}$} & C3L1 & 858.3 & 99.69 & 99.28 & 5.19 & 5.81 & 0.91 & 878.0 & 948 & 1.08 \\
\hline & C3L2 & 1759.0 & 99.82 & 99.28 & 5.31 & 5.69 & 1.73 & 798.0 & 895 & 1.12 \\
\hline & C3L3 & 2949.0 & 99.37 & 99.82 & 5.23 & 5.00 & 2.24 & 557.0 & 576 & 1.03 \\
\hline \multirow{8}{*}{$\begin{array}{l}\text { S690 SHS } \\
50 \times 50 \times 5\end{array}$} & C4L1 & 426.0 & 50.47 & 50.44 & 4.99 & 2.02 & 0.48 & 690.0 & 754 & 1.09 \\
\hline & C4L2 & 668.5 & 50.47 & 50.47 & 4.76 & 2.24 & 0.71 & 637.0 & 586 & 0.92 \\
\hline & C4L3 & 905.5 & 50.45 & 50.43 & 4.82 & 2.18 & 0.93 & 562.0 & 508 & 0.90 \\
\hline & C4L4 & 1220.0 & 50.67 & 50.51 & 4.79 & 2.21 & 1.18 & 391.0 & 347 & 0.89 \\
\hline & C4L5 & 1529.0 & 50.40 & 50.40 & 4.79 & 2.21 & 1.60 & 248.0 & 228 & 0.92 \\
\hline & C4L6 & 1700.0 & 50.60 & 50.40 & 4.95 & 2.05 & 1.72 & 201.0 & 194 & 0.97 \\
\hline & C4L7 & 1860.0 & 50.53 & 50.48 & 4.93 & 2.07 & 1.77 & 166.0 & 163 & 0.98 \\
\hline & C4L8 & 2150.0 & 50.60 & 50.52 & 4.84 & 2.16 & 2.04 & 119.0 & 122 & 1.03 \\
\hline \multirow{3}{*}{$\begin{array}{l}\text { S690 SHS } \\
100 \times 100 \times 5.6\end{array}$} & C5L1 & 858.0 & 100.43 & 100.53 & 5.67 & 5.33 & 1.03 & 1571.0 & 1563 & 1.00 \\
\hline & C5L2 & 1760.0 & 100.50 & 100.52 & 5.72 & 4.78 & 1.66 & 1420.0 & 1392 & 0.98 \\
\hline & C5L3 & 2950.0 & 100.70 & 100.59 & 5.78 & 6.22 & 3.00 & 680.0 & 677 & 0.99 \\
\hline Mean & & & & & & & & & & 1.01 \\
\hline $\mathrm{COV}$ & & & & & & & & & & 0.06 \\
\hline
\end{tabular}

Table 2: Details of ambient tests on CHS columns made from T590 high strength steel [27]

\begin{tabular}{lccccccccc}
\hline Specimens & Label & $\begin{array}{c}\mathrm{L} \\
(\mathrm{mm})\end{array}$ & $\begin{array}{c}\mathrm{D}_{\text {nom }} \\
(\mathrm{mm})\end{array}$ & $\begin{array}{c}\mathrm{D}_{\text {inner }} \\
(\mathrm{mm})\end{array}$ & $\begin{array}{c}\mathrm{t} \\
(\mathrm{mm})\end{array}$ & $\begin{array}{c}\omega_{0} \\
(\mathrm{~mm})\end{array}$ & $\begin{array}{c}\mathrm{N}_{\mathrm{u}, \text { test }} \\
(\mathrm{kN})\end{array}$ & $\begin{array}{c}\mathrm{N}_{\mathrm{u}, \mathrm{FE}} \\
(\mathrm{kN})\end{array}$ & $\mathrm{N}_{\mathrm{u}, \mathrm{FE}} / \mathrm{N}_{\mathrm{u}, \text { test }}$ \\
\hline \multirow{5}{*}{ CHS T590 } & AS1 & 1490 & 355.6 & 330.62 & 12.49 & 1.49 & 10254.0 & 9780 & 0.95 \\
& BS1 & 1490 & 323.9 & 303.38 & 10.26 & 1.49 & 7961.0 & 7209 & 0.91 \\
& AL1 & 4490 & 355.6 & 330.12 & 12.74 & 4.49 & 10857.0 & 9829 & 0.91 \\
& BL1 & 4490 & 323.9 & 302.14 & 10.88 & 4.49 & 7812.0 & 7206 & 0.92 \\
\hline Mean & & & & & & & & & 0.92 \\
COV & & & & & & & & & 0.02 \\
\hline
\end{tabular}


Table 3: Summary of SHS and RHS steel column test at elevated temperature reported by [13].

\begin{tabular}{|c|c|c|c|c|c|c|c|}
\hline Specimens & Label & $\begin{array}{c}\theta \\
\left({ }^{\circ} \mathrm{C}\right) \\
\end{array}$ & $\begin{array}{c}\mathrm{L} \\
(\mathrm{mm})\end{array}$ & End-Condition & $\begin{array}{c}\mathrm{N}_{\mathrm{u}, \text { test }, \theta}, \\
(\mathrm{kN})\end{array}$ & $\begin{array}{c}\mathrm{N}_{\mathrm{u}, \mathrm{FE}, \theta} \\
(\mathrm{kN})\end{array}$ & $\mathrm{N}_{\mathrm{u}, \mathrm{FE}, \theta} / \mathrm{N}_{\mathrm{u}, \text { test }, \theta}$ \\
\hline \multirow{3}{*}{ RHS $120 \times 60 \times 3.6$} & S02 & 400 & 360 & Fixed & 408 & 413.3 & 1.01 \\
\hline & S03 & 550 & 360 & Fixed & 257 & 239.5 & 0.93 \\
\hline & S06 & 700 & 360 & Fixed & 74 & 77.1 & 1.04 \\
\hline \multirow{3}{*}{ SHS $160 \times 160 \times 5$} & $\mathrm{~L} 2$ & 400 & 1840 & Pinned & 760 & 812.6 & 1.07 \\
\hline & L5 & 550 & 1840 & Pinned & 467 & 449.3 & 0.96 \\
\hline & L6 & 700 & 1840 & Pinned & 130 & 135.5 & 1.04 \\
\hline \multirow{3}{*}{ RHS $120 \times 60 \times 3.6$} & L08 & 400 & 1840 & Pinned & 242 & 206.8 & 0.85 \\
\hline & L10 & 550 & 1840 & Pinned & 186 & 195.4 & 1.05 \\
\hline & L05 & 700 & 1840 & Pinned & 71 & 71.0 & 1.00 \\
\hline Mean & & & & & & & 1.00 \\
\hline $\mathrm{COV}$ & & & & & & & 0.07 \\
\hline
\end{tabular}

Table 4: Summary of hollow section parametric study variables

\begin{tabular}{|c|c|c|c|c|c|c|}
\hline Section & Material & Section & $\mathrm{h} / \mathrm{b}$ & Buckling axis & Temperatures $\left({ }^{\circ} \mathrm{C}\right)$ & $\bar{\lambda}_{\theta}$ \\
\hline \multirow{4}{*}{ SHS/RHS } & S690QL & SHS $100 \times 100 \times 10$ & 1.00 & - & \multirow{6}{*}{$200,400,600,800$} & \multirow{6}{*}{$0.1-2.2$} \\
\hline & S690QL & RHS $150 \times 100 \times 10$ & 1.50 & Major and Minor & & \\
\hline & S700MC & SHS $100 \times 100 \times 10$ & 1.00 & - & & \\
\hline & S700MC & RHS $150 \times 100 \times 10$ & 1.50 & Major and Minor & & \\
\hline \multirow{2}{*}{ CHS } & S690QL & CHS $100 \times 10$ & - & - & & \\
\hline & $\mathrm{S} 700 \mathrm{MC}$ & CHS $100 \times 10$ & - & - & & \\
\hline
\end{tabular}

Table 5: Summary of the S690QL material properties [5].

\begin{tabular}{lcccccc}
\hline Temperatures & $\begin{array}{c}\mathrm{E} \\
(\mathrm{GPa})\end{array}$ & $\begin{array}{c}\mathrm{E}_{0.2} \\
(\mathrm{GPa})\end{array}$ & $\begin{array}{c}\mathrm{f}_{0.2} \\
\left(\mathrm{~N} / \mathrm{mm}^{2}\right)\end{array}$ & $\begin{array}{c}\mathrm{f}_{1.0} \\
\left(\mathrm{~N} / \mathrm{mm}^{2}\right)\end{array}$ & $\mathrm{n}$ & $\mathrm{m}$ \\
\hline 20 & 199.29 & 3.41 & 706.33 & 717.34 & 101.98 & 1.52 \\
100 & 189.70 & 10.01 & 690.00 & 707.96 & 32.50 & 1.52 \\
200 & 191.16 & 9.71 & 667.50 & 688.78 & 32.23 & 1.78 \\
300 & 183.35 & 14.89 & 651.00 & 699.59 & 20.08 & 2.39 \\
400 & 176.67 & 16.92 & 643.00 & 673.09 & 16.52 & 2.88 \\
500 & 178.00 & 13.59 & 567.00 & 610.21 & 19.03 & 5.17 \\
600 & 149.71 & 15.21 & 442.00 & 499.94 & 14.07 & 3.15 \\
700 & 76.27 & 9.99 & 222.50 & 249.19 & 9.74 & 7.62 \\
800 & 53.74 & 4.05 & 70.00 & 80.06 & 7.97 & 3.75 \\
\hline
\end{tabular}


Table 6: Summary of the S700MC material properties [5].

\begin{tabular}{lcccccc}
\hline Temperatures & $\begin{array}{c}\mathrm{E} \\
(\mathrm{GPa})\end{array}$ & $\begin{array}{c}\mathrm{E}_{0.2} \\
(\mathrm{GPa})\end{array}$ & $\begin{array}{c}\mathrm{f}_{0.2} \\
\left(\mathrm{~N} / \mathrm{mm}^{2}\right)\end{array}$ & $\begin{array}{c}\mathrm{f}_{1.0} \\
\left(\mathrm{~N} / \mathrm{mm}^{2}\right)\end{array}$ & $\mathrm{n}$ & $\mathrm{m}$ \\
\hline 20 & 224.69 & 24.52 & 749.33 & 793.30 & 13.77 & 2.40 \\
100 & 204.63 & 24.82 & 744.00 & 768.96 & 13.08 & 2.03 \\
200 & 217.55 & 21.37 & 703.00 & 749.20 & 14.80 & 2.80 \\
300 & 210.53 & 26.05 & 735.00 & 798.48 & 12.28 & 4.17 \\
400 & 205.57 & 25.94 & 691.00 & 770.08 & 11.54 & 3.41 \\
500 & 190.11 & 19.16 & 610.00 & 672.69 & 14.34 & 4.00 \\
600 & 178.25 & 23.77 & 511.50 & 559.70 & 9.34 & 6.86 \\
700 & 140.76 & 14.29 & 350.00 & 367.35 & 10.96 & 3.91 \\
800 & 86.74 & 5.51 & 175.00 & 179.82 & 14.87 & 1.74 \\
\hline
\end{tabular}

Table 7: Comparison between the FE and predicted resistances.

\begin{tabular}{|c|c|c|c|c|c|}
\hline Section & Material & $\mathrm{N}_{\mathrm{u}, \mathrm{FE}, \theta} / \mathrm{N}_{\mathrm{u}, \mathrm{EC}, \theta}$ & EN 1993-1-2 [16] & $\mathrm{N}_{\mathrm{u}, \mathrm{FE}, \theta} / \mathrm{N}_{\mathrm{u}, \text { prop }, \theta}$ & Proposal \\
\hline \multirow{10}{*}{$\begin{array}{l}\text { SHS/RHS } \\
\text { and CHS }\end{array}$} & \multirow{5}{*}{ S690QL } & No. & 241 & No. & 241 \\
\hline & & Mean & 1.13 & Mean & 1.11 \\
\hline & & $\mathrm{COV}$ & 0.10 & $\mathrm{COV}$ & 0.09 \\
\hline & & Max & 1.39 & Max & 1.34 \\
\hline & & Min & 0.90 & Min & 0.87 \\
\hline & \multirow{5}{*}{ S700MC } & No. & 240 & No. & 240 \\
\hline & & Mean & 1.13 & Mean & 1.04 \\
\hline & & $\mathrm{COV}$ & 0.04 & $\mathrm{COV}$ & 0.03 \\
\hline & & Max & 1.30 & Max & 1.15 \\
\hline & & Min & 1.04 & Min & 0.96 \\
\hline
\end{tabular}

Table 8: Summary of the reliability assessment results.

\begin{tabular}{ccccccc}
\hline Section & Material & Criteria & \multicolumn{2}{c}{ EN 1993-1-2 [16] } & \multicolumn{2}{c}{ Proposal } \\
\hline & & 1 & $0.00 \%$ & Pass & $0.00 \%$ & Pass \\
& \multirow{2}{*}{ S690QL } & 2 & $15.98 \%$ & Pass & $18.45 \%$ & Pass \\
SHS/RHS & & 3 & -0.09 & Pass & -0.08 & Pass \\
\cline { 3 - 7 } and CHS & & 1 & $0.00 \%$ & Pass & $0.00 \%$ & Pass \\
& \multirow{2}{*}{ S700MC } & 2 & $0.00 \%$ & Pass & $15.37 \%$ & Pass \\
& & 3 & -0.11 & Pass & -0.03 & Pass \\
\hline
\end{tabular}




\section{Figures}

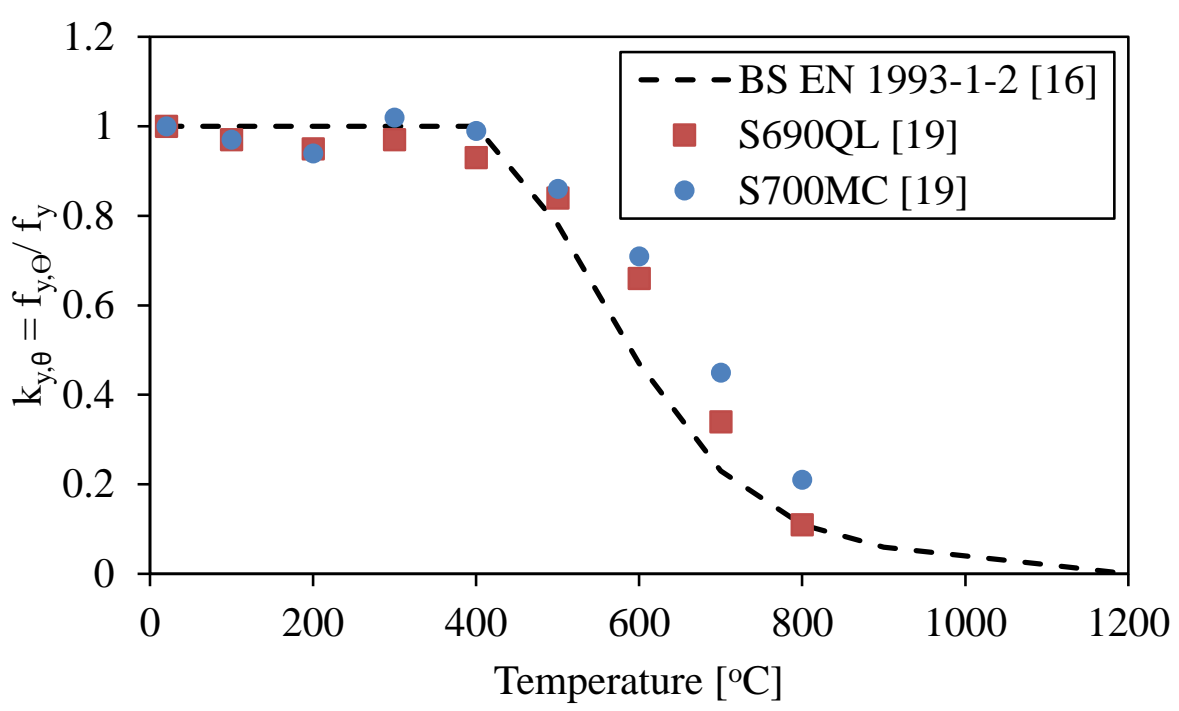

Figure 1: Retention factors for the yield strength for different grades of HSS compared with Eurocode values 


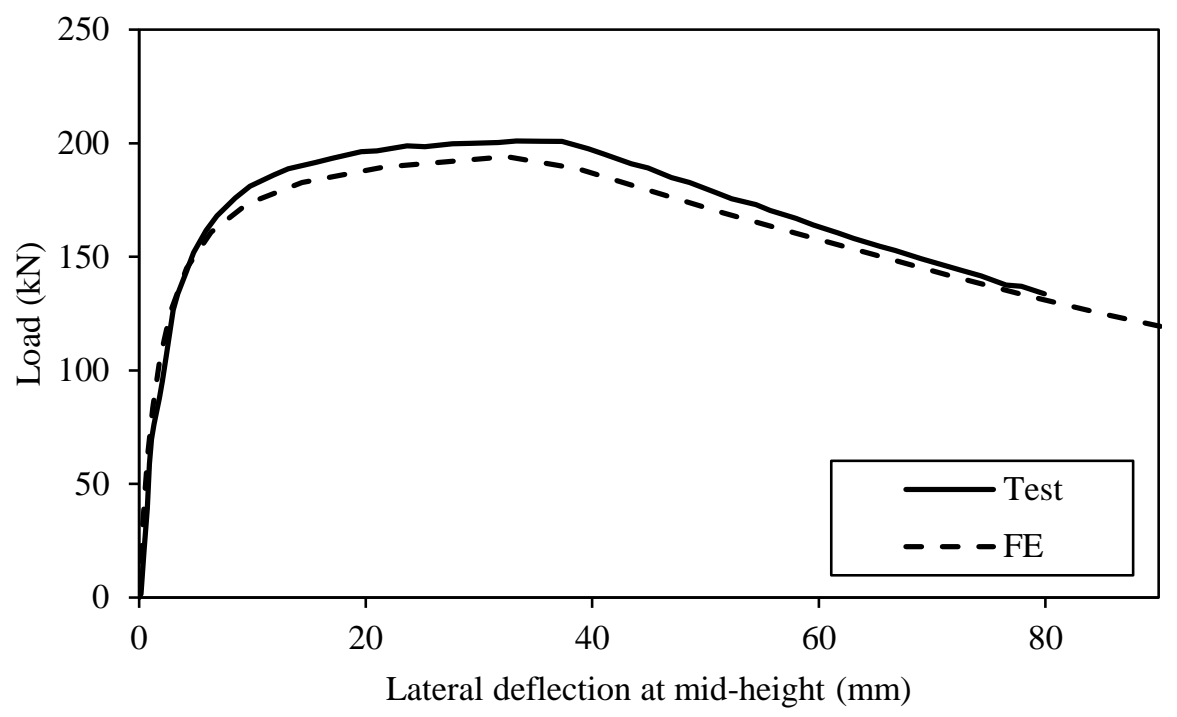

(a)

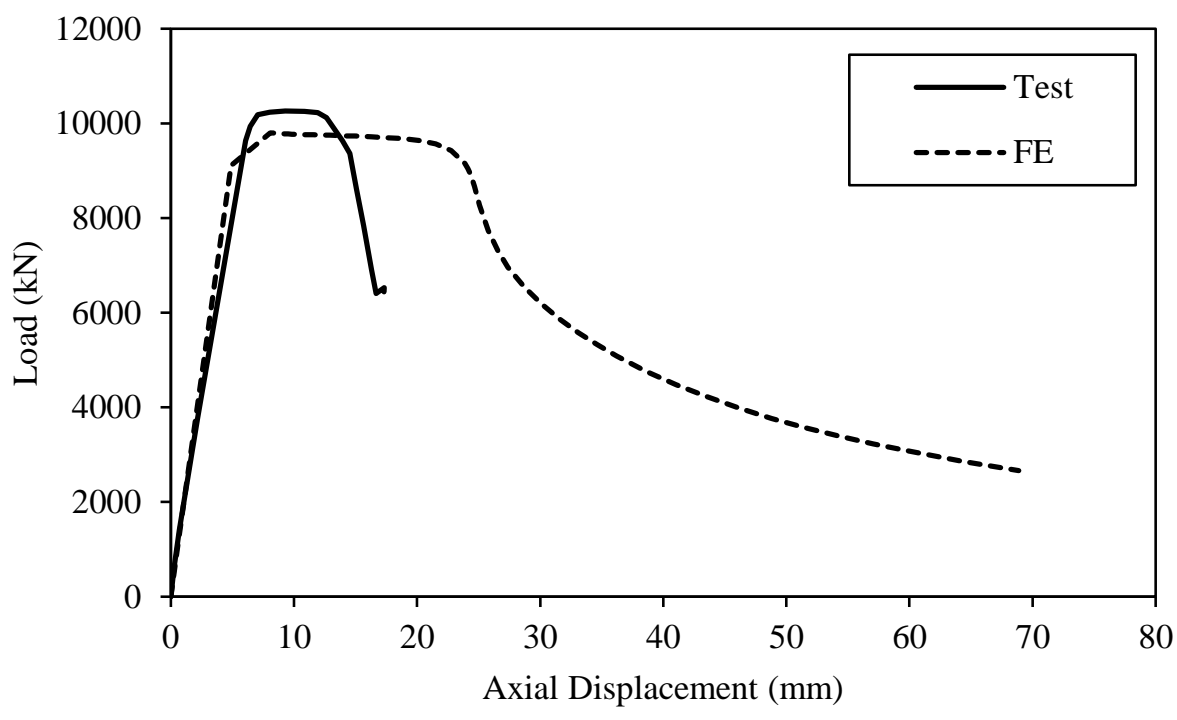

(b)

Figure 2: Comparison of the experimental and numerical load-deflection responses for (a) SHS specimen C4L6 [26] and (b) CHS column AS1 [27] 


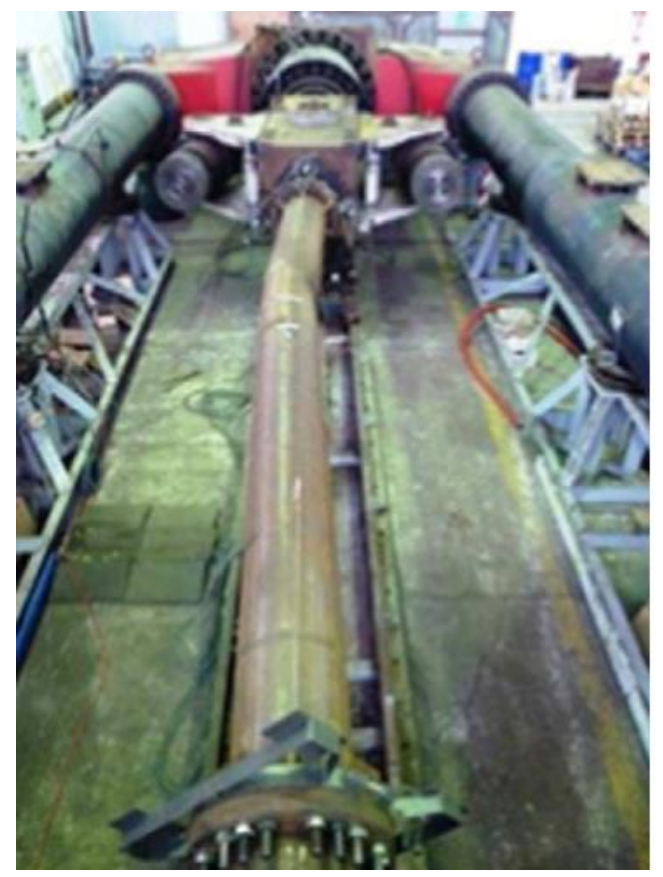

(a)

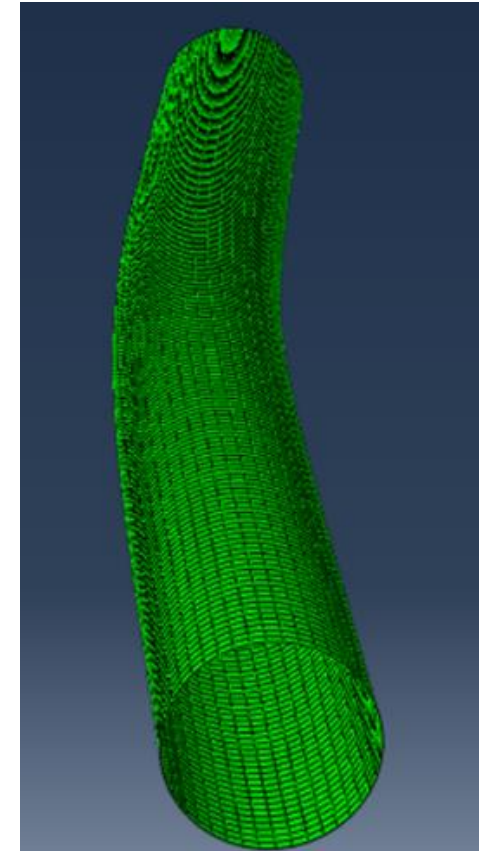

(b)

Figure 3: Image of the failure shape of the AL1 CHS specimen from (a) the experimental programme [27] and (b) the FE model 


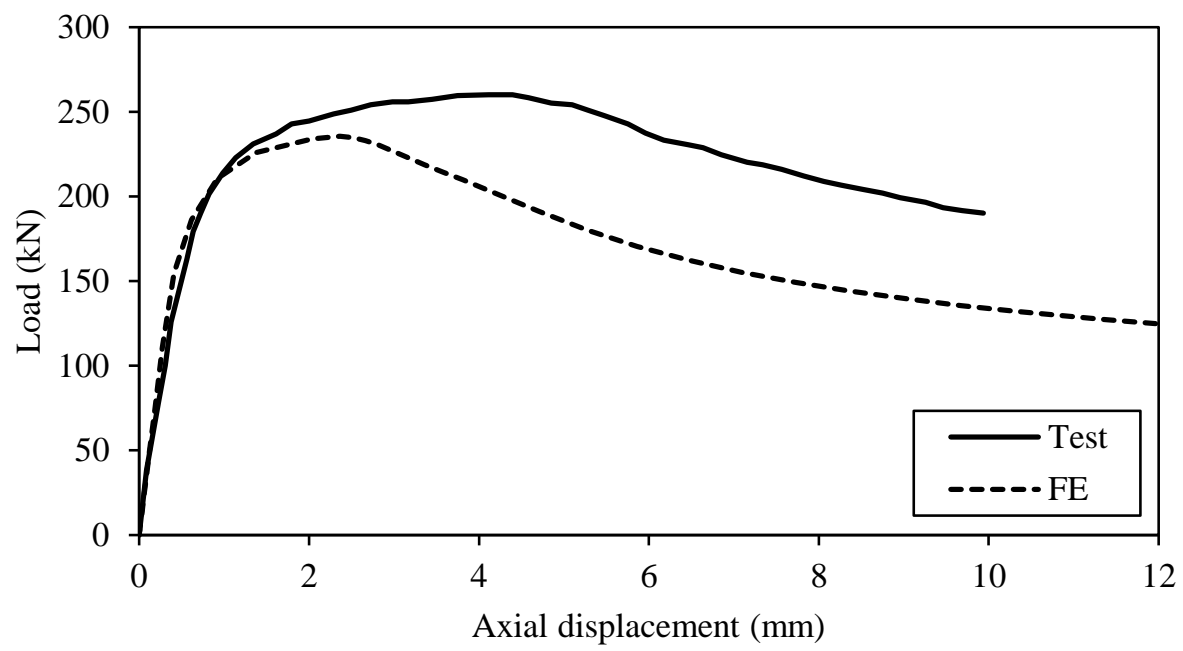

(a)

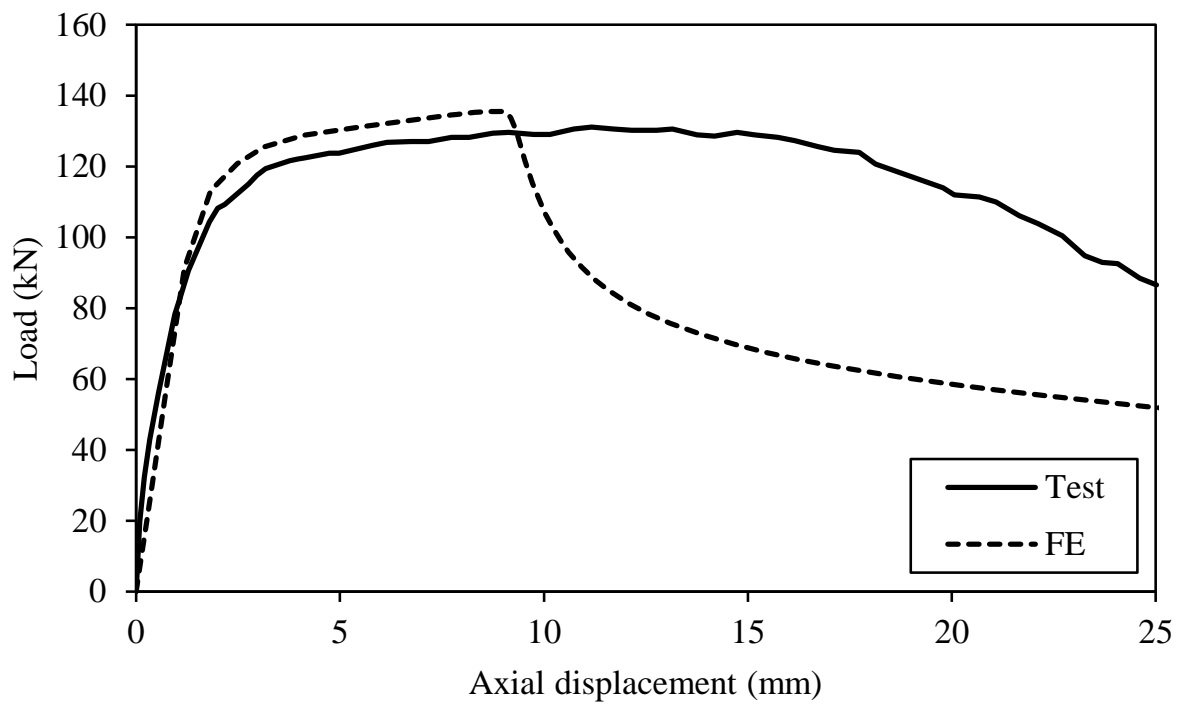

(b)

Figure 4: Comparison of the experimental and numerical load-deflection response for (a) stub column S03 with a $120 \times 60 \times 3.6$ RHS cross-section and (b) slender column L6 with a $160 \times 160 \times 5$ SHS cross-section [13] 


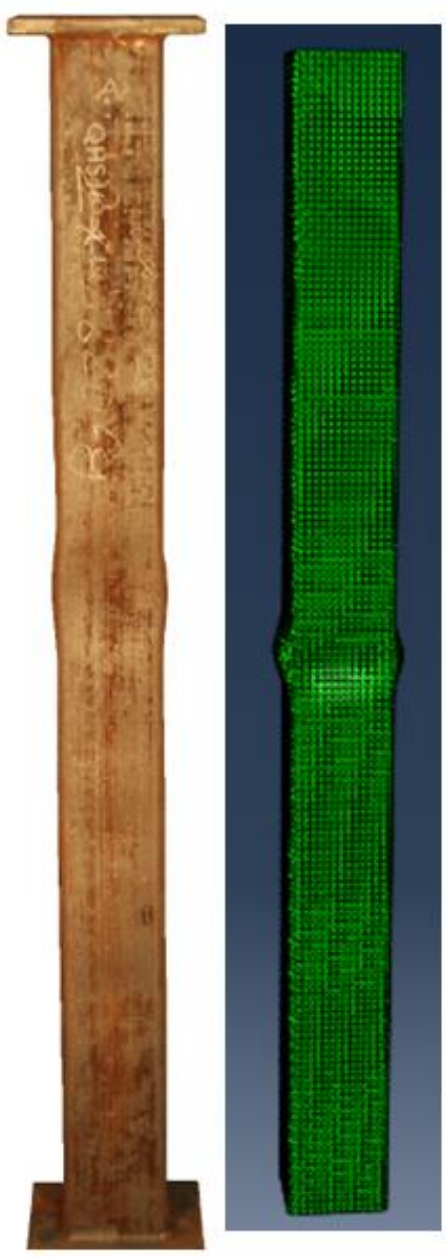

(a) 

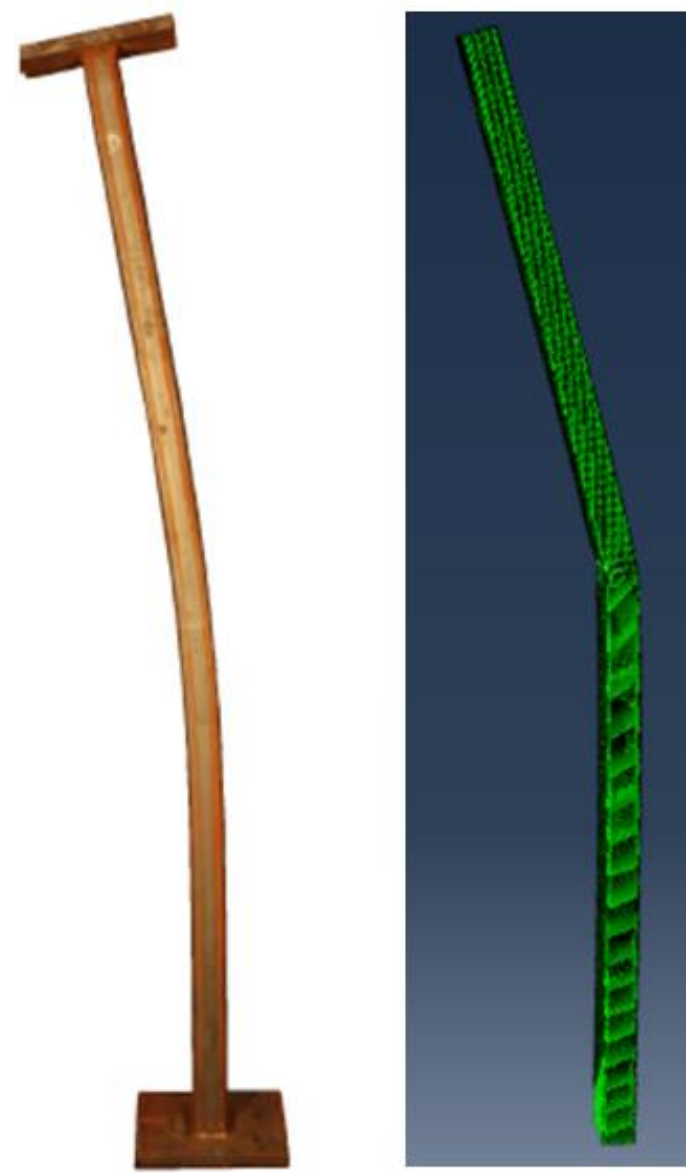

(b)

Figure 5: Images of the failure modes from the test specimens [29] and FE simulations for (a) column L6 with a $160 \times 160 \times 5$ SHS cross-section and (b) column L10 wth a $120 \times 60 \times 3.6$ RHS cross-section. 


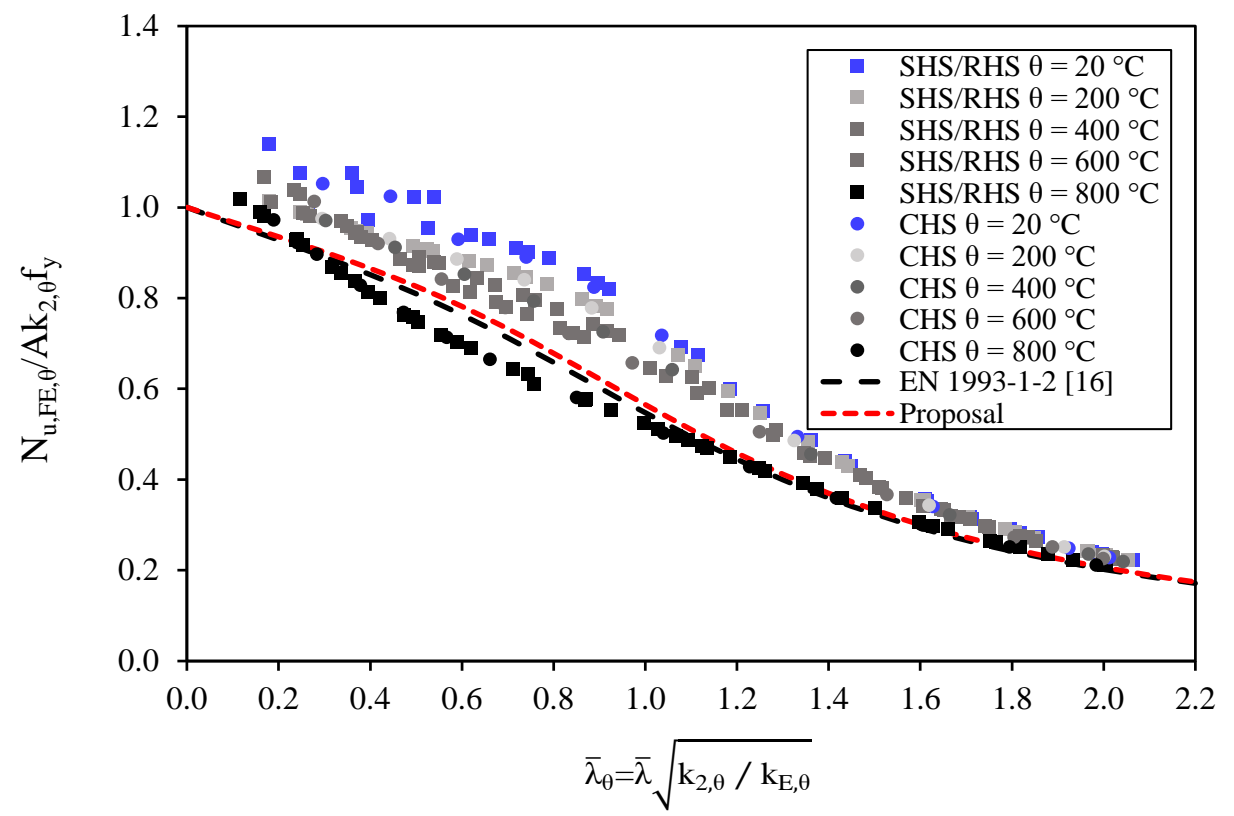

(a)

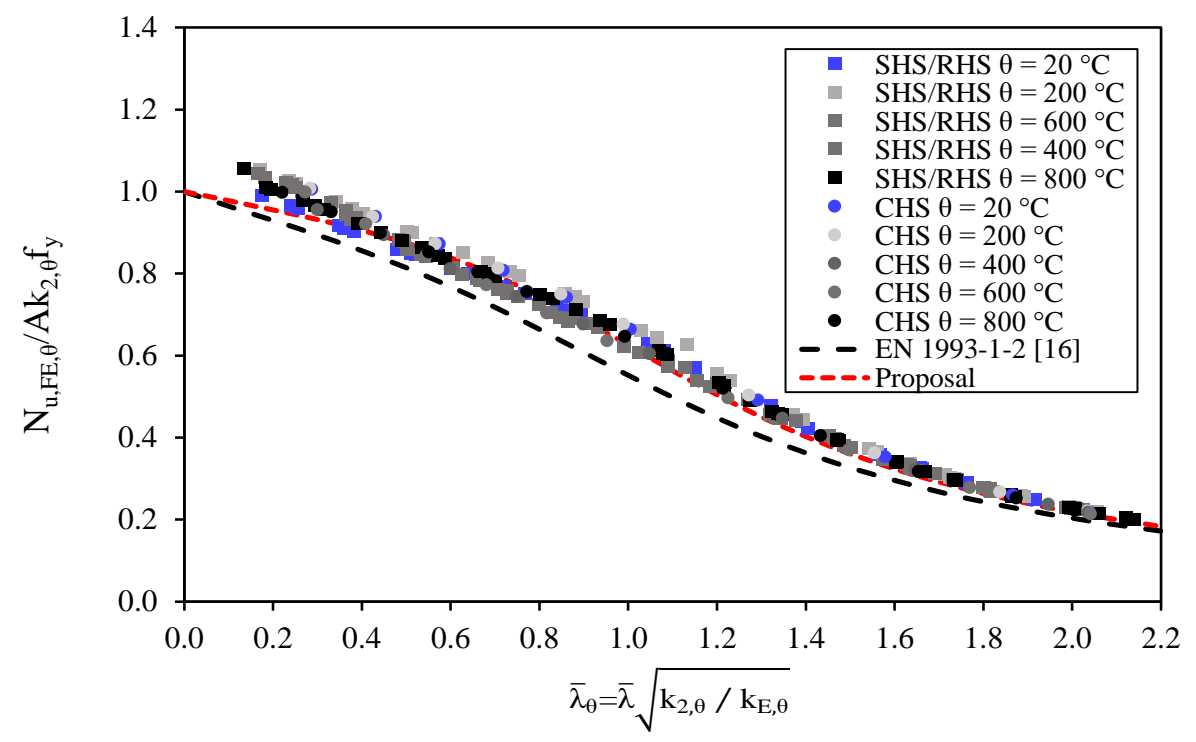

(b)

Figure 6: Comparison of FE results with the Eurocode and proposed buckling curves for SHS, RHS and CHS columns made from (a) S690QL and (b) S700MC HSS 


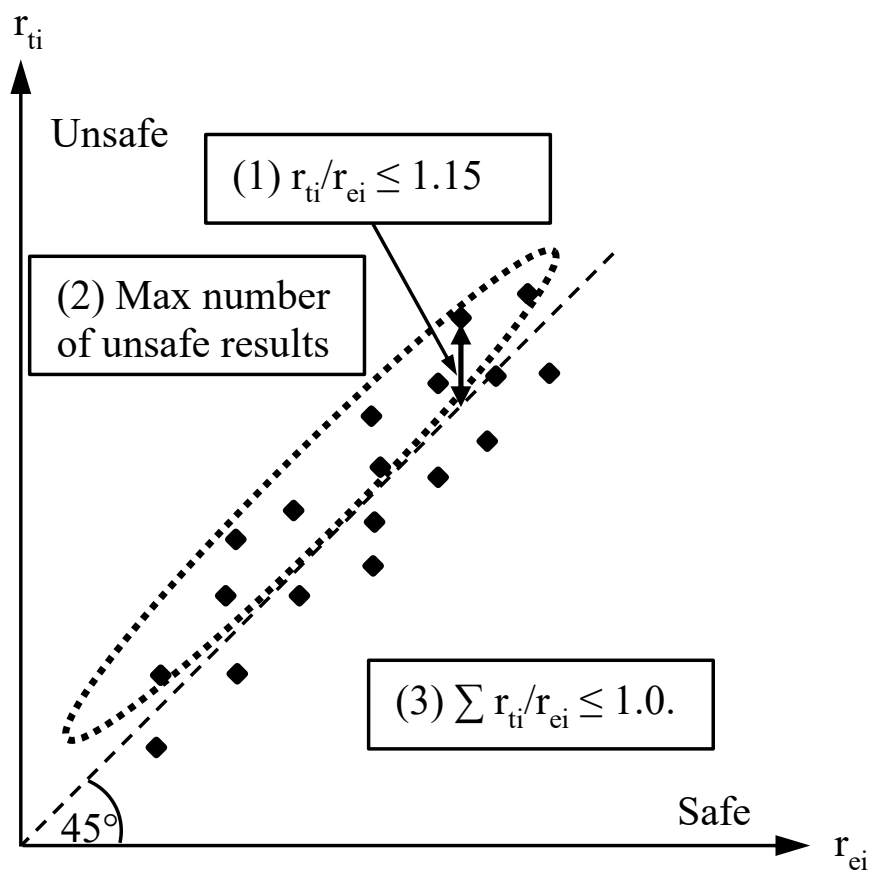

Figure 7: Schematic representation of the reliability criteria set out by Kruppa [33]. 